\title{
Ethnic differences in prevalence of asthma symptoms and bronchial hyperresponsiveness in New Zealand schoolchildren
}

\author{
PHILIP K PATTEMORE, M INNES ASHER, ADRIAN C HARRISON, \\ EDWIN A MITCHELL, HAROLD H REA, ALISTAIR W STEWART
}

From the Departments of Paediatrics and Community Health, School of Medicine, University of Auckland, and the Department of Respiratory Medicine, Green Lane Hospital, Auckland, New Zeland

\begin{abstract}
Maoris and Pacific Islanders in New Zealand have a higher asthma mortality andhospital admission rates than Europeans. To determine whether difference in asthma prevalence is the major factor underlying these differences in mortality, 2053 Auckland children aged 7-10 years? (European 1084, Maori 509, Pacific Islander 460) were randomly sampled from school classes in the Auckland Urban Area, and studied by questionnaire (completed by parents) and histamine00 inhalation challenge to assess the provocative dose of histamine causing a $20 \%$ fall in $\mathrm{FEV}_{1}\left(\mathrm{PD}_{20}\right)_{\square}^{\circ}$ Maoris had the highest prevalence rates of respiratory symptoms, and Europeans had rates similar too Pacific Islanders. For "any current wheeze" for example, the prevalence in Maoris was $22 \cdot 2 \%$ compared with $16.1 \%$ and $16.3 \%$ in the Europeans and Pacific Islanders. The prevalence of diagnosed asthma was similar in the three groups. When bronchial hyperresponsiveness (defined as aD $\mathrm{PD}_{20} \leqslant 7.8 \mu \mathrm{mol}$ histamine) was considered, Europeans had the highest rates $(20 \%)$, followed by Maoris (13\%), and then Pacific Islanders (8.7\%). These differences were not accounted for byg differences in socioeconomic status, rates of smoking in the home, age, gender, or height. It is concluded that differences in asthma prevalence do not satisfactorily explain the mortality and admission rate differences, although the higher symptom prevalence in the Maoris could be relevant to the higher mortality rate. Maori and Pacific Island children with symptoms of asthma were less likely to be taking prophylactic medication than European children. It is proposed that differences inx management are important factors relevant to the increased mortality and morbidity from asthma ing Polynesians.
\end{abstract}

\section{Introduction}

Asthma prevalence and morbidity vary in different races around the world. 'In New Zealand, Polynesians (Maoris and Pacific Islanders) have rates two to five times higher than people of European origin for both asthma mortality ${ }^{23}$ and hospital admissions for asthma. ${ }^{45}$ For instance, the annual asthma mortality rates for Aucklanders 10-19 years of age from 1981 to 1983 were (per 100000 children): Europeans 2.0, Maoris $8 \cdot 0$, Pacific Islanders $11 \cdot 8 .^{2}$ Similar differences have

Address for reprint requests: Dr P K Pattemore, Medicine 1, Cente Block, Southampton General Hospital, Southampton SO9 4XY.

Accepted 14 December 1988 been found in New Zealand as a whole both for 10-19 year olds and for age standardised mortality. ${ }^{3}$ In $198 \%$ hospital admission rates for 0-14 year olds in Auck land were two to three times higher in Maoris ands Pacific Islanders than in Europeans, ${ }^{4}$ and similat results were found in all age groups for the whole of New Zealand in 1981. ${ }^{5}$ These differences imply eithew that asthma is more prevalent in Polynesians or tha Polynesians have higher case morbidity and case fatality rates from asthma than do Europeans.

There have been no satisfactory studies comparing the prevalence of asthma in Europeans, Maoris, and Pacific Islanders living in New Zealand. In this studi we examine ethnic differences in asthma prevalence in? schoolchildren. The age group of children in this studs and the survey methods used were chosen to make 
possible to compare children of European origin with similar children studied previously in New South Wales, Australia; the findings of that study have been published elsewhere. ${ }^{6}$

\section{Methods}

The study was carried out in Auckland, New Zealand, in the winter months May to August 1985. Auckland, sited on a marine isthmus, has a humid, temperate climate, and is both the largest city in New Zealand (area $1016 \mathrm{~km}^{2}$, estimated population 825200 in March 1985) and the largest population centre of Polynesian people in the world (Maoris 62 508, Pacific Islanders 56 982: Census of Population and Dwellings, 1981).

\section{SUBJECTS}

The sample size was calculated to give an $80 \%$ power of detecting an asthma prevalence rate in Polynesians 1.4 times higher than the predicted rate in Europeans. Similar studies in New South Wales, Australia, had shown detectable differences of this magnitude between European children in different areas, ${ }^{7}$ and it was considered unlikely that a smaller difference could explain the large differences in mortality and morbidity between ethnic groups. The sampling process was designed to select about 1400 European and 1000 Polynesian children by stratified two stage random sampling of standard 2 and 3 classes (age range 7-10 years) from the entire Auckland Urban Area, excluding classes for the handicapped.

In 1985 the Auckland Urban Area contained about 30000 standard 2 and 3 pupils in 1077 classes and 273 schools: three out of four of these children were of European ancestry and most of the remainder were of Polynesian ancestry. In Auckland standard 2 and 3 pupils are grouped with other levels in different combinations from school to school (for example, standard $1 / 2,2,2 / 3,3,3 / 4,1 / 2 / 3,2 / 3 / 4$, and "variable spaces"). These groupings contain differing proportions of standard and 2 and 3 pupils, and as some groupings may occur more frequently in schools drawing from particular social strata or ethnic groups it was necessary to stratify the sample. In the first stage, classes were grouped by class type into seven strata of 40-160 classes each, and randomly sampled within each stratum (in proportion to that stratum's estimated contribution to the total number of Polynesians in the sampling frame, based on Education Board and school statistics) until an estimated 1000 Polynesian children were included. In the second stage details of actual class numbers and perceived ethnicity of children were obtained from teachers; half of the European children in these classes were randomly excluded, and all children of racial groups other than
Polynesian or European were excluded.

\section{QUESTIONNAIRE}

The English language questionnaire completed by parents included questions about the personal and demographic details of the child and parents; a history of asthma symptoms, diagnosis, medication, and atopic symptoms in the child; and a history of asthma or atopy and smoking habits of the parents. This questionnaire has been found to be reproducible in European subjects. ${ }^{8}$ On the advice of resource persons within the Maori and Pacific Island communities, we used the English language questionnaire throughout the study, enclosing with it an explanatory letter in four languages (New Zealand Maori, Cook Island Maori, Samoan, and Tongan), which instructed parents to seek assistance from an English speaking person if they were unable to understand English themselves.

\section{BRONCHIAL CHALLENGE TESTING}

Participating schools were visited by a team of two to five technicians and one doctor over a three month period. Children were given a full or abbreviated histamine inhalation challenge by the method of Yan et al. ${ }^{9}$ We have previously described our application of this technique, including instrumentation and calibration. ${ }^{6}$ Asthma medication was not suspended before testing. Children whose forced expiratory volume in one second $\left(\mathrm{FEV}_{1}\right)$ fell by more than $20 \%$ from baseline after receiving a cumulative dose of $7.8 \mu \mathrm{mol}$ histamine or less were considered to have bronchial hyperresponsiveness. In these children the provocative dose resulting in a $20 \%$ fall in $\mathrm{FEV}_{1}\left(\mathrm{PD}_{20}\right)$ was obtained by graphical interpolation. $A$ PD $_{20}$ less than or equal to $1.00 \mu \mathrm{mol}$ was taken to indicate severe bronchial hyperresponsiveness. Inhaled salbutamol was given to aid recovery in any child whose $F E V_{1}$ fell significantly, and all recovered promptly.

\section{APPROVAL AND CONSENT}

The study was approved by the Department of Health, the Auckland Education Board, and the ethics committee of Green Lane Hospital, Auckland. Informed consent was obtained from school principals and from the parents of all participating children. Individual test results were communicated by letter to all parents, and to the family doctors of children with bronchial hyperresponsiveness or diagnosed asthma.

\section{NON-PARTICIPANTS}

If a child did not return a questionnaire another was issued, and if necessary the home was visited by a team of medical students to help parents complete the questionnaire. Schools were revisited where two or more children had been absent on the initial day of 
testing owing to sickness or other reasons.

\section{DATA ANALYSIS}

Data was analysed using the SAS statistical package. The significance of differences was assessed by contingency table analysis. The Mantel-Haenszel test was used to assess the effect of controlling separately for socioeconomic status and for smoking in the home. Multiple logistic regression was used to control simultaneously for several continuous and categorical variables. A probability level of 0.01 was chosen to indicate a significant difference, to reduce the likelihood of detecting spurious differences in a large number of comparisons (type 1 errors). Preliminary analysis indicated substantial differences between Maori and Pacific Island children. The differences between these groups and the Europeans were obscured by considering Polynesians as one group (despite the higher power of the latter analysis), so the results are reported separately; the power of the resulting analysis was calculated retrospectively.

\section{DEFINITIONS}

Race was defined from the response to the question "What race is your child?" with options listed as "European," "New Zealand Maori," "Pacific Islander (specify)," and "Other (specify)." For any child of mixed ancestry, the child was classified as Maori if the answer included "New Zealand Maori," Pacific Islander if the answer included "Pacific Islander" without "New Zealand Maori," and European if the mixture was solely of different caucasian origins. Pacific Islanders from islands other than the Polynesian islands (Samoa, Tonga, Niue, Tokelau, and the Cook Islands) were excluded, as were children of mixed EuropeanAsian descent.

Socioeconomic group (1-6: high-low) was defined from a revision ${ }^{10}$ of the Elley-Irving socioeconomic index for New Zealand occupations, on the basis of the father's present or most recent occupation if he lived at home and otherwise the mother's occupation.

The four main symptoms (wheeze, exercise wheeze, breathless attacks, and night cough) are collectively referred to as respiratory symptoms. Symptoms occurring in the 12 months before testing are called current symptoms.

Recent upper respiratory tract infection was defined from the child's positive answer at the time of testing to the question "Have you had a cold in the last week?"

Asthma prevalence criteria There is no single ideal or agreed criterion by which to measure asthma prevalence.' To facilitate comparison with other studies we have assessed the three ethnic groups on five criteria $\stackrel{\sim}{x}$ that have been used in other studies, which for $\vec{F}$ convenience are collectively referred to as asthma prevalence criteria. These criteria are: any wheeze ever (including exercise wheeze), any current wheeze $\frac{\overline{0}}{\overline{0}}$ (including exercise wheeze), any respiratory symptoms $\vec{\nabla}$ ever, any current respiratory symptom, and asthma $\cong$ diagnosed ever. The number of children with con- $\%$ comitant bronchial hyperresponsiveness in each $\overrightarrow{0}$ category has also been assessed.

\section{Results}

Similar participation rates were achieved in Europeans (84\%) and Polynesians (83\%). Informa- $\vec{\sigma}$ tion regarding age, sex, race, and presence or absence $\infty$

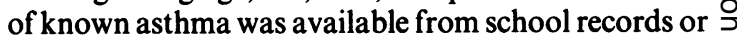
other sources for $72 \%$ of European and $75 \%$ of $\vec{z}$ Polynesian non-participants.

\section{NON-PARTICIPANTS}

Five schools, covering 84 children in the sample, did not consent to the study. For individual reasons a further 326 children (161 Europeans and 165 Polynesians) did not participate despite follow up. The major reasons were: questionnaire not obtained-120; absent from school and not tested (due to sickness, relocation, etc)-107; parental non-consent-92. $\stackrel{\unrhd}{2}$ There was no significant difference in age or sex $\overrightarrow{\vec{A}}$ distribution between participants and non-partici- $\frac{3}{3}$ pants, and the percentage of known asthma among non-participants did not differ significantly from the rate of diagnosed asthma among participating children in the same ethnic group.

\section{PARTICIPANTS}

Among the children taking part there were $1084 \stackrel{3}{3}$ Europeans, 509 Maoris, and 460 Pacific Islanders, selected from 160 classes in 123 schools. Demographic data for these children are shown in table 1.

The three ethnic groups were similar in age and sex distribution. The highest proportions of children born in New Zealand and lifelong residents of New Zealand $\bar{N}$ (total period resident overseas less than six months) ? occurred in Maoris. Europeans were more likely than $\tilde{O}$ Pacific Islanders to have been born in New Zealand, $N$ but had a similar lifelong residence rate. A considerable difference in socioeconomic distribution wase observed; $70.7 \%$ of Europeans were in the upper three $\frac{\odot}{\Phi}$ social groups (1-3) compared with $19 \cdot 5 \%$ of Maoris $\stackrel{?}{+}$ and $18.1 \%$ of Pacific Islanders. The three groups 0 differed significantly from each other in the prevalence of smoking in the home: $\mathbf{4 4 . 4 \%}$ of European children $\triangle$ lived with a smoker, compared with $77.6 \%$ of Maori $\stackrel{\mathbb{Q}}{\alpha}$ and $53.9 \%$ of Pacific Island children. 
Table 1 Demographic characteristics of children (percentages of ethnic group)

\begin{tabular}{|c|c|c|c|c|c|c|}
\hline & \multirow{2}{*}{$\begin{array}{l}\text { European } \\
(n=1084)\end{array}$} & \multirow{2}{*}{$\begin{array}{l}\text { Maori } \\
(n=509)\end{array}$} & \multirow{2}{*}{$\begin{array}{l}\text { Pacific Islander } \\
(n=460)\end{array}$} & \multicolumn{3}{|c|}{ Significance $(p<)$} \\
\hline & & & & $E M$ & $E I$ & $M I$ \\
\hline $\begin{array}{l}\text { Age (y) } \\
6 / 7 / 11 \\
8 \\
9 \\
10\end{array}$ & $\begin{array}{l}1.2 \\
37.2 \\
49.8 \\
11.8\end{array}$ & $\begin{array}{r}2 \cdot 8 \\
38 \cdot 3 \\
44 \cdot 2 \\
14 \cdot 7\end{array}$ & $\begin{array}{r}2.6 \\
33 \cdot 5 \\
48 \cdot 3 \\
15 \cdot 6\end{array}$ & NS & NS & NS \\
\hline $\begin{array}{l}\text { Sex } \\
\text { Male } \\
\text { Female }\end{array}$ & $\begin{array}{l}50 \cdot 3 \\
49 \cdot 7\end{array}$ & $\begin{array}{l}51 \cdot 5 \\
48.5\end{array}$ & $\left.\begin{array}{l}49.4 \\
50.6\end{array}\right\}$ & NS & NS & NS \\
\hline $\begin{array}{l}\text { Born in New Zealand } \\
\text { Lifelong New Zealand resident }\end{array}$ & $\begin{array}{l}93 \cdot 4 \\
88 \cdot 2\end{array}$ & $\begin{array}{l}99 \cdot 2 \\
97 \cdot 4\end{array}$ & $\begin{array}{l}84 \cdot 8 \\
84 \cdot 6\end{array}$ & $\begin{array}{l}0.001 \\
0.001\end{array}$ & $\begin{array}{l}0.001 \\
\mathrm{NS}\end{array}$ & $\begin{array}{l}0.001 \\
0.001\end{array}$ \\
\hline $\begin{array}{l}\text { Socioeconomic group } \\
1 \\
2 \\
3 \\
4 \\
5 \\
6 \\
\text { Unclassified }\end{array}$ & $\begin{array}{r}11.4 \\
27.6 \\
31.7 \\
18.9 \\
5.7 \\
1.5 \\
3.1\end{array}$ & $\begin{array}{r}1.4 \\
4.9 \\
13.2 \\
38 \cdot 1 \\
18 \cdot 1 \\
8.6 \\
15.7\end{array}$ & $\left.\begin{array}{r}1.1 \\
3.7 \\
13.3 \\
35.2 \\
19.8 \\
14.8 \\
12.2\end{array}\right\}$ & 0.001 & 0.001 & NS \\
\hline
\end{tabular}

EM-European $v$ Maori; EI-European $v$ Pacific Islander; MI-Maori $v$ Pacific Islander.

INDIVIDUAL RESPIRATORY SYMPTOMS

The three ethnic groups are compared in figure 1 for reported lifetime and current prevalence rates of each of the four respiratory symptoms. Wheeze and nocturnal cough were the most commonly reported symptoms in all three groups, and current nocturnal cough was more common than current wheeze.

The pattern of differences between the ethnic groups was similar for all four symptoms, both for lifetime and for current prevalence. Maori children reported the highest rates of all symptoms; the rates for Europeans differed little from those of Pacific Islanders, except that Pacific Islanders reported significantly more current night cough than Europeans. No significant differences were observed for the prevalence of children who reported more than 12 episodes of wheeze in the previous 12 months (Europeans $2.2 \%$, Maoris $2 \cdot 4 \%$, Pacific Islanders $1 \cdot 1 \%$ ).

\section{BRONCHIAL HYPERRESPONSIVENESS}

Ninety nine per cent of children successfully com- pleted bronchial challenge tests. Table 2 shows the rates of bronchial hyperresponsiveness and the distribution by $\mathbf{P D}_{20}$ values in each ethnic group. We observed a significantly higher rate of bronchial hyperresponsiveness among Europeans than among Maoris or Pacific Islanders. Maori children displayed rates intermediate between those of European and Pacific Island children, and these did not differ significantly from those of Pacific Islanders. There were no significant differences in the rates for severe bronchial hyperresponsiveness, although again the highest rate occurred in European children and the lowest in Pacific Island children.

\section{CRITERIA OF ASTHMA PREVALENCE}

In figure 2 the three ethnic groups are compared for the five chosen criteria. The figure also shows how the rates are affected if only children with coexisting bronchial hyperresponsiveness are included in the numerator. Although the absolute rates differ widely

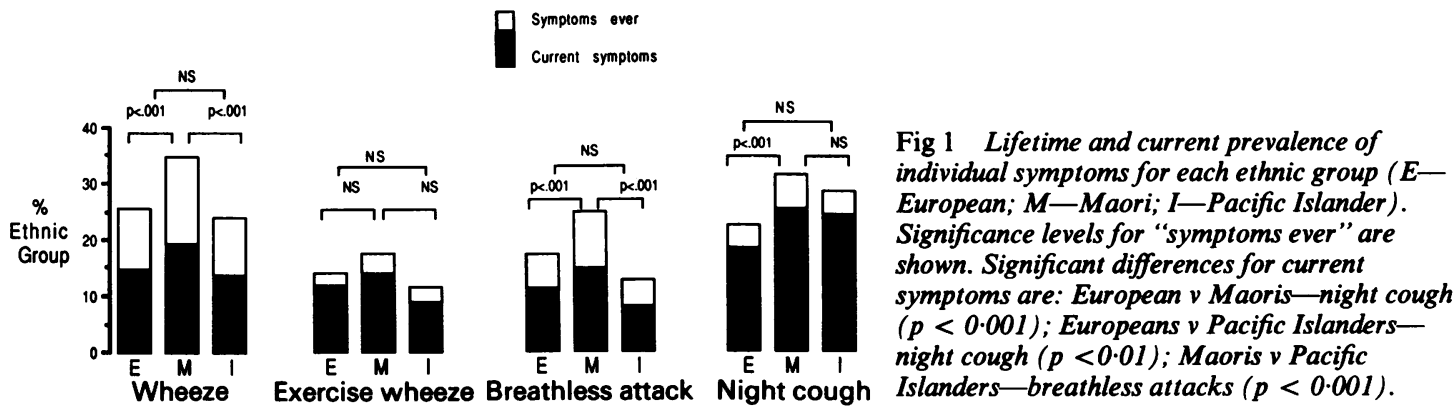


Table 2 Bronchial hyperresponsiveness: total rates and distribution by $P D_{20}$ (percentages of ethnic group)

\begin{tabular}{|c|c|c|c|c|c|c|c|}
\hline & & \multirow{2}{*}{$\begin{array}{l}\text { European } \\
(n=1084)\end{array}$} & \multirow{2}{*}{$\begin{array}{l}\text { Maori } \\
(n=509)\end{array}$} & \multirow{2}{*}{$\begin{array}{l}\text { Pacific Islander } \\
(n=460)\end{array}$} & \multicolumn{3}{|c|}{ Significance $(p<)$} \\
\hline & & & & & $E M$ & $E I$ & $M I$ \\
\hline \multicolumn{2}{|c|}{ All subjects with bronchial hyperresponsiveness (\%) } & $20 \cdot 2$ & $13 \cdot 2$ & $8 \cdot 7$ & 0.001 & 0.001 & NS \\
\hline $\mathrm{PS}_{20}(\mu$ mol histamine $)$ & $\begin{array}{l}4 \cdot 01-7 \cdot 8 \\
2 \cdot 01-4 \cdot 0 \\
1 \cdot 01-2 \cdot 0 \\
0 \cdot 01-1 \cdot 0\end{array}$ & $\begin{array}{l}7 \cdot 7 \\
4 \cdot 7 \\
3.9 \\
3.8\end{array}$ & $\begin{array}{l}4 \cdot 1 \\
2 \cdot 9 \\
2 \cdot 9 \\
3 \cdot 1\end{array}$ & $\begin{array}{l}3 \cdot 3 \\
2 \cdot 4 \\
1 \cdot 7 \\
1 \cdot 3\end{array}$ & $\overline{\mathrm{NS}}$ & NS & $\mathrm{NS}^{*}$ \\
\hline
\end{tabular}

between the criteria, the three ethnic groups bear a consistent relationship to each other.

The lifetime and current prevalence rates of any wheeze and any respiratory symptom were higher in Maoris than in Europeans, and current prevalence rates of both were higher in Maoris than in Pacific Islanders. Prevalence rates for Pacific Islanders did not differ substantially from those of Europeans and there was no significant difference between the groups in the prevalence of asthma diagnosed ever. For any current wheeze the rates were: Europeans $16 \cdot 1 \%$, Maoris $22.2 \%$, Pacific Islanders $16 \cdot 3 \%$ (European $v$ Maoris $\chi^{2}=8.45, \mathrm{p}<0.01$; European $v$ Pacific Islanders $\chi^{2}=0.0, \mathrm{p}>0.5$, NS; Maoris $v$ Pacific Islanders $\left.\chi^{2}=5 \cdot 0, \mathrm{p}>0 \cdot 01, \mathrm{NS}\right)$.

A different trend is seen for these categories when only those children with concurrent bronchial hyperresponsiveness are considered. The rates for European children significantly exceed those for Pacific Island children. The rates in Maori children are intermediate; they are not significantly different from European rates, and differ from Pacific Islander rates only for the category of children with asthma diagnosed ever and bronchial hyperresponsiveness.

From figure 2 it is also clear that bronchial hyperresponsiveness is found more frequently in European children with symptoms than in Maori or Pacific
Islander children with symptoms: $44 \%$ of Europeans $\stackrel{+}{+}$ who reported any wheeze ever had bronchial hyper- $\omega$ responsiveness compared with $27 \%$ of Maoris and $\vec{\infty}$ $22 \%$ of Pacific Islanders.

INTERACTION WITH SOCIAL AND OTHER FACTORS For the sample as a whole, socioeconomic status did not significantly affect reported rates of symptoms, but $\frac{\bar{\alpha}}{\bar{C}}$ bronchial hyperresponsiveness was more common in the upper three socioeconomic groups than in the $\infty$ lower three $(19.7 \% \cdot v 12.7 \% ; \mathrm{p}<0.001)$. The ethnic ${ }^{\circ}$ differences in symptom rates or bronchial hyperresponsiveness were not, however, altered significantly when socioeconomic status was controlled for (Mantel-Haenszel test).

Overall, children who lived with a smoker reported $\stackrel{\mathbb{\perp}}{\mathbb{Q}}$ respiratory symptoms more commonly than those $\overrightarrow{\overrightarrow{0}}$ who did not $(45.2 \% \vee 36.7 \%$; $<0.001)$, but in 3 Maoris and Pacific Islanders there was no significant difference in bronchial hyperresponsiveness rates be-:0 tween these groups. European children who lived with a smoker had a lower rate of bronchial hyper-o responsiveness than those who did not $(16.4 \% v \stackrel{\sim}{\otimes}$ $23.2 \% ; p<0.01$ ). Again, however, the ethnic differ- 0 ences in symptom rates and bronchial hyperrespon -3 . siveness rates persisted after we had controlled for theô presence or absence of smokers in the home.

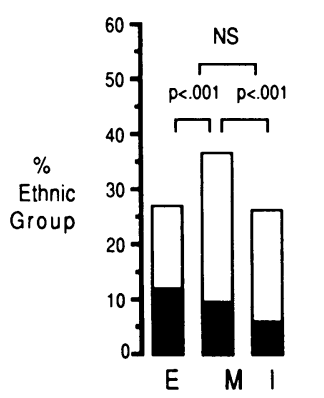

Any wheeze ever

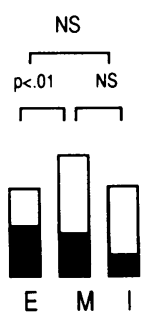

Any current wheeze

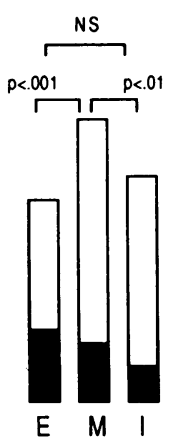

Resp symptoms ever children with BHR
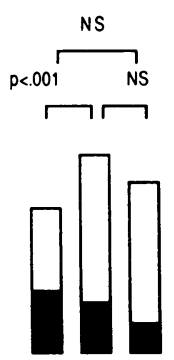

E M I

Current resp symptoms

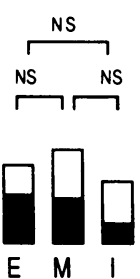

Asthma diagnosec ever
Fig 2 Rates of five criteria of asthma prevalence for each ethnic group (E-European N M-Maori; I-Pacific Islander). Significance level (S) overall criteria are shown. స Significant differences for the different criteria in conjunctign with bronchial hyperresponsiveness (BHR) are: $\mathbb{D}$ Europeans v Maoris-nil; Europeans $v$ Pacific Islander all five criteria $(p<0.001)$ 웅 Maoris v Pacific Islanders "asthma diagnosed ever" \) $(p<0.01)$. 
For bronchial hyperresponsiveness and for each of the asthma prevalence criteria, multiple logistic regression analysis was used to assess the independent effects of ethnicity, socioeconomic group, smoking in the home, age, gender, height, and baseline FVC. Ethnicity was a significant independent factor in each analysis. Maori ethnic group had a significant (positive) effect on any wheeze ever $(\mathrm{p}=0.0006)$, any symptom ever $(\mathrm{p}=0.003)$, and diagnosed asthma $(\mathrm{p}=$ 0.010 ), and weaker effects on bronchial hyperresponsiveness $(\mathrm{p}=0.029)$ and any current wheeze $(\mathrm{p}=$ 0.020). European ethnic group had a significant (positive) effect $(p<0.0001)$ on the presence of bronchial hyperresponsiveness. In the case of any current symptom, Maori ethnicity had a significant effect only when European ethnicity was not included in the model. Baseline FVC had a negative effect on each of the criteria $(p=0.001-0.05)$, and height had a positive effect on any wheeze ever $(\mathrm{p}=0.012)$, any symptom ever $(\mathrm{p}=0.009)$, and any current symptom $(p=0.003)$. Male gender had a positive effect on any wheeze ever $(\mathrm{p}=0.0005)$ and on any symptom ever $(\mathrm{p}=0.009)$; and smoking in the home had a positive effect on any symptom ever $(\mathrm{p}=0 \cdot 014)$. Age and socioeconomic group showed no significant independent effects in any of these analyses.

The rates of reported symptoms and of bronchial hyperresponsiveness did not differ between lifelong New Zealand residents and those who had lived more than six months overseas nor between children born in New Zealand and those born elsewhere.

\section{RELATED CONDITIONS}

The three ethnic groups are compared in table 3 for prevalence of hay fever, eczema, bronchitis under the age of 2 years and recent upper respiratory tract infection. The only significant differences were that Pacific Islanders had a higher rate of hay fever than did Europeans, and Maoris had a higher rate of early bronchitis than did either Europeans or Pacific Islanders. The rates of recent upper respiratory tract infection were similar for the three groups, and did not affect rates of bronchial hyperresponsiveness significantly.

The rate of atopic conditions (hay fever or eczema) in children with any wheeze ever was $66.7 \%$ for Europeans, $\mathbf{5 7 \cdot 2 \%}$ for Maoris, and $\mathbf{6 6 . 4 \%}$ for Pacific Islanders (no significant differences). For children with any wheeze ever but without bronchial hyperresponsiveness the rates of atopic conditions were again similar in the three groups (Europeans 59\%, Maoris $54 \%$, Pacific Islanders $61 \%$ ) and were nearly double the rates in children with neither bronchial hyperresponsiveness nor wheeze.

The rates of reported asthma in parents of study children are shown in table 3 . Asthma was significantly more common in Maori mothers than European mothers, but for fathers no significant differences were found.

\section{DIAGNOSIS AND TREATMENT OF CHILDREN WITH SYMPTOMS}

Among the children with any current wheeze a diagnosis of asthma had been made in $61 \%$ of European, $54 \%$ of Maori, and $40 \%$ of Pacific Island children (Europeans $v$ Pacific Islanders: $p<0.001$; other differences not significant).

The proportion of parents indicating that their child had at some time received "medication for asthma" was $19.9 \%$ for Europeans, $25.0 \%$ for Maoris, and $14.6 \%$ for Pacific Islanders (Maoris $v$ Pacific Islanders: $\mathrm{p}<0.001$; other differences not significant). Of children with any current wheeze such treatment was reported for $75 \%$ of European, $67 \%$ of Maori, and $52 \%$ of Pacific Island children (Europeans $v$ Pacific Islanders: $\mathrm{p}<0.001$; other differences not significant). In this group of current wheezers, bronchodilators (beta agonist or theophylline) were currently being used by $55 \%$ of European, $43 \%$ of Maori, and $21 \%$ of Pacific Island children (Europeans $v$ Pacific Islanders: $p<0.001$; Maoris $v$ Pacific Islanders: $p<0.01$; Europeans $v$ Maoris: not significant); prophylactic

Table 3 Lifetime prevalence of related conditions in children and parents (percentages of children in ethnic group)

\begin{tabular}{|c|c|c|c|c|c|c|}
\hline & \multirow{2}{*}{$\begin{array}{l}\text { European } \\
(n=1084)\end{array}$} & \multirow{2}{*}{$\begin{array}{l}\text { Maori } \\
(n=509)\end{array}$} & \multirow{2}{*}{$\begin{array}{l}\text { Pacific Islander } \\
(n=460)\end{array}$} & \multicolumn{3}{|c|}{ Significance $(p<)$} \\
\hline & & & & $E M$ & $E I$ & $M I$ \\
\hline $\begin{array}{l}\text { Children: } \\
\text { Hay fever } \\
\text { Eczema } \\
\text { Bronchitis in infancy } \\
\text { Recent upper respiratory tract infection }\end{array}$ & $\begin{array}{l}27 \cdot 5 \\
25 \cdot 6 \\
14 \cdot 9 \\
35 \cdot 8\end{array}$ & $\begin{array}{l}29 \cdot 7 \\
28 \cdot 9 \\
25 \cdot 7 \\
39 \cdot 3\end{array}$ & $\begin{array}{l}35 \cdot 2 \\
28 \cdot 9 \\
15 \cdot 0 \\
38 \cdot 0\end{array}$ & $\begin{array}{l}\text { NS } \\
\text { NS } \\
0.001 \\
\text { NS }\end{array}$ & $\begin{array}{l}0.001 \\
\text { NS } \\
\text { NS } \\
\text { NS }\end{array}$ & $\begin{array}{l}\text { NS } \\
\text { NS } \\
0.001 \\
\text { NS }\end{array}$ \\
\hline $\begin{array}{l}\text { Parental asthma: } \\
\text { Mothers } \\
\text { Fathers }\end{array}$ & $\begin{array}{r}10.9 \\
9.3\end{array}$ & $\begin{array}{r}16 \cdot 1 \\
9 \cdot 8\end{array}$ & $\begin{array}{r}14 \cdot 8 \\
9 \cdot 1\end{array}$ & $\begin{array}{l}0 \cdot 01 \\
\text { NS }\end{array}$ & $\begin{array}{l}\text { NS } \\
\text { NS }\end{array}$ & $\begin{array}{l}\text { NS } \\
\text { NS }\end{array}$ \\
\hline
\end{tabular}

EM-European $v$ Maori; EI-European $v$ Pacific Islander; MI-Maori $v$ Pacific Islander. 
medications (inhaled cromoglycate or corticosteroids) were being used by $25 \%$ of Europeans, $13 \%$ of Maoris, and $4 \%$ of Pacific Islanders (Europeans $v$ Pacific Islanders: $p<0.001$; other differences not significant).

\section{Discussion}

In New Zealand a higher proportion of Polynesians than Europeans die from asthma. ${ }^{23}$ Studies for the country as a whole have shown that asthma mortality rates standardised for age and asthma mortality rates in the 0-14 year age group are more than five times higher in the Maori population than in the European population. ${ }^{311}$ National rates for Pacific Islanders lie between the Maori and European rates; but, when Auckland (the principal residence site of Pacific Islanders in New Zealand) is considered on its own, Pacific Islanders have higher asthma mortality rates than do Maoris. ${ }^{2}$ Socioeconomic status does not account for the differences in mortality rates. ${ }^{12}$

National hospital admission rates for asthma in the 0-14 year age group are lowest in Europeans and highest in Pacific Islanders (more than double the European rate); the rate in Maoris is intermediate. ${ }^{5}$ Studies in Auckland have shown similar ethnic differences in admission rates for children. ${ }^{4}$

The simplest explanation for these figures is that common factors underly the higher asthma morbidity and the higher mortality in Maoris and Pacific Islanders. We have examined the possiblity that these differences are due to differences in asthma prevalence. We considered that this possibility would require the presence of prevalence rates at least 1.4 times higher in Maoris and Pacific Islanders than in Europeans. None of the asthma prevalence criteria shows such a difference, although for lifetime and current prevalences of any wheeze and any respiratory symptom Maoris had rates 1.35-1.39 times those of Europeans, and the differences were significant. There were no significant differences for the prevalence of asthma diagnosed ever or frequent current wheezing. As a crude estimate of asthma prevalence in adults we examined reported rates of asthma in the parents of study children, and found that Maori mothers reported asthma significantly more commonly than European mothers (1.48 times higher), but that no differences were found for fathers. Conceivably the higher rates of symptoms and of maternal asthma in Maoris may be a true reflection of a higher asthma prevalence, despite their having a lower point prevalence of bronchial hyperresponsiveness than Europeans. The magnitude of the difference, however, could only partially account for the higher asthma mortality and morbidity in Maoris.

Pacific Islanders, on the other hand, had symptom
Pattemore, Asher, Harrison, Mitchell, Rea, Stewar rates similar to those of Europeans (with the exception: of current night cough), and lower rates of bronchias hyperresponsiveness and bronchial hyperresponsive ness combined with symptoms. On retrospective cale culation, the study had more than $90 \%$ power tô detect rates 1.4 times higher in Pacific Islanders that Europeans (had such differences existed) for the prevalences of any wheeze ever, any respiratory symp tom ever, and any current respiratory symptom; a type II error in this comparison is therefore highly unlikely $\overrightarrow{\dot{\vec{\omega}}}$ Factors other than asthma prevalence must be invoked to explain why Pacific Islanders have highe asthma mortality and morbidity rates tham Europeans.

Bronchial hyperresponsiveness was found in only $a$ proportion of children with symptoms. For Europearo children this proportion ( $44 \%$ of those with ang wheeze ever) closely matches figues obtained for children of European origin both in Dunedin, News Zealand (about $1000 \mathrm{~km}$ south of Auckland), where $49.5 \%$ of recurrent wheezers had bronchial hypers responsiveness, ${ }^{13}$ and in inland and coastal New Southe Wales, Australia (over $2000 \mathrm{~km}$ west of Auckland) where respectively $44 \%$ and $38 \%$ of children with wheezing ever showed bronchial hyperresponsiveness. By comparison, Maoris and Pacific Islanders in Auck land who had symptoms were much less likely to be्द hyperresponsive: only $27 \%$ of Maori children an $22 \%$ of Pacific Island children with any wheeze eve? were found to have bronchial hyperresponsiveness.

There are several possible explanations for the lowe? rate of bronchial hyperresponsiveness in Polynesian children reporting symptoms. It is important first t $Q$. consider potential sources of bias in the questionnaire and in the measurement of bronchial hypera responsiveness.

Inadequate understanding of the English language questionnaire may have led to inadvertent over reporting of symptoms by Maori and Pacific Islan\& parents, but this is unlikely. At the time of the study English was the first language of nearly all Maoris in Auckland. Recent Pacific Islander immigrants migh? have difficulty with English, but $85 \%$ of the Pacifie Island children were lifelong residents of New Zealand, and some facility with English would bie expected in their parents. This hypothesis was tested ip parents of 8-10 year old Samoan children (the larges $\omega^{2}$ Pacific Islander population group in Auckland), wh\& were asked to complete both the English questionnaire used in this study and a Samoan translation. Three oug of 45 were unable to understand the Samoan question ${ }^{+}$ naire, whereas none reported inability to understan the English one (M I Asher, P K Pattemore, unpub lished data).

Socioeconomic and ethnic group may influence reporting of illness, owing to differing community an 
personal perceptions of health. Maoris and Pacific Islanders in Auckland are predominantly in the lower three socioeconomic groups. A study of general symptom reporting by diary in South Auckland ${ }^{14}$ showed that these ethnic groups reported symptoms less commonly than Europeans, in the face of higher morbidity from several common conditions, and the ethnic differences were independent of socioeconomic status.

In our study there was no significant difference between symptom rates in the upper three and lower three socioeconomic groups, and ethnic differences in symptom rates persisted after socioeconomic group had been controlled for. Health workers within the Maori community have pointed out that a socioeconomic index based on occupation does not necessarily correspond to social standing within the Maori and Pacific Island communities, and that Maoris as a group have a poor health image and feel pessimistic about their community health status. ${ }^{15}$ The influence of such factors awaits further study.

Other potentially confounding factors, such as recent respiratory infections and passive smoking, were examined. Studies investigating the effect of respiratory infections on measures of bronchial responsiveness in normal subjects have yielded conflicting results. ${ }^{16}{ }^{17}$ In our study the reported rates of recent upper respiratory tract infection were similar in the various groups and bronchial hyperresponsiveness rates were not appreciably altered by a recent infection. In adults cigarette smoking has been shown to increase bronchial responsiveness, ${ }^{18}$ and passive smoking may increase the rate of bronchial hyperresponsiveness $^{19}$ or of symptoms ${ }^{20}$ in children. We found a higher symptom rate among children who lived with smokers than among those who did not. The reason for the lower rate of bronchial hyperresponsiveness among European children who lived with a smoker is not clear: one possible explanation is that in European families parents of children sensitive to smoke may alter their smoking practices. The ethnic differences in symptom and bronchial hyperresponsiveness rates remained after we had controlled for smoking in the home. The observed ethnic differences were also independent of age, gender, height, and baseline FVC, although each of the latter, except age, also had some independently significant effects on the rates of some symptoms.

Having considered the above factors, we would argue that the ethnic differences in rates of reported symptoms and bronchial hyperresponsiveness are likely to be valid. Two implications follow-firstly, that Maori children have significantly more asthma like symptoms than either European or Pacific Island children and, secondly, that Polynesians with asthma like symptoms are less likely to show bronchial hyperresponsiveness than similar European children. Polynesian children may predominantly suffer from a different type of wheezing illness ${ }^{21}$ owing to genetic or environmental influences. Nevertheless, the similar rates of other atopic conditions in wheezy children in the three groups argues against a substantive difference in the type of condition being reported. In common with Waite $e t$ al ${ }^{22}$ we could find no effect of birthplace or residential history on prevalence of asthma symptoms in children living in New Zealand. That study did, however, indicate a lower prevalence of asthma in children living in the Tokelau islands than in Tokelauan children in New Zealand.

We conclude that asthma prevalence does not provide a satisfactory basis to account for the ethnic differences in asthma mortality and hospital admission rates, and other explanations must be sought. The New Zealand mortality studies have emphasised lack of adequate prophylactic treatment as one factor common to many cases of death from asthma. ${ }^{23}$ We found that, although Maoris had the highest overall asthma diagnosis and treatment rates, probably as a result of their higher symptom rates, Maori and Pacific Island children with wheezing in the past year were less likely to be diagnosed as having asthma and treated than European children, and this was particularly true of treatment with inhaled corticosteroids or cromoglycate. Management of asthma in Polynesians is an important area for further study. We propose that relative undertreatment of asthmatic patients suffering from symptoms is a contributing factor leading to increased rates of acute severe asthma and consequently higher hospital admission and mortality rates for Maoris and Pacific Islanders in New Zealand.

This study would not have been possible without the excellent work of $\mathbf{J}$ Innes-Walker (research nurse), J Mulder (senior technician), and technicians L Gregory, F Jackson, and K Stirling. We also wish to thank the Auckland Education Board, the school staff, and the parents and children for their cooperation with the study, and the Medical Research Council of New Zealand and the Asthma Foundation of New Zealand for financial support. PKP was funded by the Medical Research Council of New Zealand, the Mackie Estates Research Fund of the Auckland Asthma Society, and the Auckland Medical Research Foundation. AWS is funded by the Medical Research Council of New Zealand.

\section{References}

1 Gregg I. Epidemiological aspects. In: Clark TJH, Godfrey S, eds. Asthma. 2nd ed. London: Chapman and Hall, 1983:242-84.

2 Sutherland DC, Beaglehole R, Fenwick J, Jackson RT, Mullins P, Rea HH. Death from asthma in Auckland: 
circumstances and validation of causes. $\mathrm{NZ} \mathrm{Med} \mathrm{J}$ 1984;97:845-8.

3 Sears MR, Rea HH, Beaglehole R, et al. Asthma mortality in New Zealand: a two year national study. NZ Med J 1985;98:271-5.

4 Mitchell EA, Cutler DR. Paediatric admissions to Auckland Hospital for asthma from 1970-1980. NZ Med J 1984;97:67-70.

5 Mitchell EA, Borman B. Demographic characteristics of asthma admissons to hospitals. NZ Med J 1986; 99:576-9.

6 Asher MI, Pattemore PK, Harrison AC, et al. International comparison of the prevalence of asthma symptoms and bronchial hyper-responsiveness. Am Rev Respir Dis 1988;138:524-9.

7 Britton WJ, Woolcock AJ, Peat JK, Sedgwick CJ, Lloyd DM, Leeder SR. Prevalence of bronchial hyperresponsiveness in children: the relationship between asthma and skin reactivity to allergens in two communities. Int J Epidemiol 1986;15:202-9.

8 Salome CM, Peat JK, Britton WJ, Woolcock AJ. Bronchial hyperresponsiveness in two populations of Australian schoolchildren. I. Relation to respiratory symptoms and diagnosed asthma. Clin Allergy 1987; 17:271-81.

9 Yan K, Salome C, Woolcock AJ. Rapid method for measurement of bronchial responsiveness. Thorax 1983;38:760-5.

10 Johnston R. A revision of socio-economic indices for New Zealand. Wellington: New Zealand Council for Educational Research, 1983.

11 Sears MR, Rea HH, Fenwick J, et al. Deaths from asthma in New Zealand. Arch Dis Child 1986;61:6-10.

12 Sears MR, O'Donnell TV, Rea HH. Asthma mortality and socio-economic status [letter]. $N Z \mathrm{Med} J$ 1985; 98:765.

13 Sears MR, Jones DT, Holdaway MD, Hewitt CJ,
Pattemore, Asher, Harrison, Mitchell, Rea, Stewart

Flannery EM, Herbison GP, Silva PA. Prevalence of bronchial reactivity to inhaled methacholine in New Zealand children. Thorax 1986;41:283-9.

14 West SR, Harris BJ. The effect of personal characteristics on response levels in a health survey. $N Z$ Med $J \overline{\bar{\omega}}$ 1983;96:666-8.

15 Pomare EW. Maori health: new concepts and initiatives. NZ Med J 1986;99:410-1.

16 Laitinen LA, Kava T. Bronchial reactivity followinguncomplicated influenza $A$ infection in healthy subjects. and in asthmatic patients. Eur $J$ Respir Dis 1980; 106(suppl):51-8.

17 Jenkins CR, Breslin ABX. Upper respiratory tract infections and airway reactivity in normal and asthmatic. subjects. Am Rev Respir Dis 1984;130:879-83.

18 Welty C, Weiss ST, Tager IB, et al. The relationship of airways reponsiveness to cold air, cigarette smoking, $\vec{\sigma}$ and atopy to respiratory symptoms and pulmonaryo function in adults. Am Rev Respir Dis 1984;130:윽 198-203.

19 O'Connor GT, Weiss ST, Tager IB, Speizer FE. The effect of passive smoking on pulmonary function and $\stackrel{2}{ }$ nonspecific bronchial responsiveness in a population- $\frac{\rho}{-}$ based sample of children and young adults. Am $\operatorname{Rev} \rightarrow$ Respir Dis 1987;135:800-4.

20 Schenker MB, Samet JM, Speizer FE. Risk factors for. childhood repiratory disease: the effect of host factors and home environmental exposures. Am Rev Respir Diss 1983;128:1038-43.

21 Brewster DR, Pearse V. Hospital admissions for wheez-⿹ำ ing in Polynesian children. NZ Med J 1979;89:339-41.

22 Waite DA, Eyles EF, Tonkin SL, O'Donnell TV. Asthma prevalence in Tokelauan children in two environments. $\overline{\overline{0}}$ Clin Allergy 1980;10:71-5.

23 Rea HH, Sears MR, Beaglehole R, et al. Lessons from the? national asthma mortality study: circumstances sur=rounding death. NZ Med J 1987;100:10-3. 